\title{
DOG AFTER DOG REVISITED
}

\author{
Sigrid Beck \& Arnim von Stechow, \\ Universität Tübingen \\ sigrid.beck@uni-tuebingen.de, arnim.stechow@uni-tuebingen.de
}

\begin{abstract}
This paper presents a compositional semantic analysis of pluractional adverbial modifiers like 'dog after dog' and 'one dog after the other'. We propose a division of labour according to which much of the semantics is carried by a family of plural operators. The adverbial itself contributes a semantics that we call pseudoreciprocal.
\end{abstract}

\section{Introduction}

The topic of this paper is the semantic analysis of the sentences in (1). (1a,b) contain the adverbial modifiers 'one after the other' and 'dog after dog', respectively, which add to the simple (1') information on how the overall event of the dogs entering the room is to be divided into subevents based on a division of the group of dogs into individual dogs. We call these adverbials pluractional adverbials, following e.g. Lasersohn's (1995) use of the term pluractionality for the division of larger eventualities into subeventualities.

(1) a. These three dogs entered the room one after the other.

b. They entered the room dog after $\mathbf{d o g}$.

These three dogs entered the room.

The type of situation described by (1a) (and also by (1b) if the referent of 'they' is the same as the referent of 'the three dogs') is depicted informally in (2). We will aim to derive this fact by associating with $(1 \mathrm{a}, \mathrm{b})$ (roughly) the truth conditions in (3); that is, we will propose a compositional semantics for $(1 \mathrm{a}, \mathrm{b})$ that derives approximately the truth conditions in (3), and (3) serves to capture our intuitions about the situations in which $(1 \mathrm{a}, \mathrm{b})$ would be considered true.

(2) a. These three dogs entered the room one after the other.

b. $\quad$ D3 $\rightarrow$ D2 $\rightarrow$ D1 $" x \rightarrow y "=x$ enters the room after $y$

(3) These three dogs entered the room, and the entering can be divided into a sequence of subevents in each of which one of the dogs enters, and the dogs can be divided into a sequence of individual dogs each of which entered in one of the subevents.

While we largely concentrate on the particular examples in (1), the phenomenon as such is of course more general. Other examples of reduplicative adverbials like 'dog after dog' are given in (4), and other examples of the 'one ... the other' type are provided in (5). These data were collected informally from the web.

(4) a. This mystery offers puzzle within puzzle.

b. She laid book upon book and built a staircase long enough to climb up and look over the wall.

c. The Wall of Tears is a very big wall that was built, stone over stone by the prisoners when Isabela was a penal colony back in 1946. 
(5) a. Because life's interaction is like a series of boxes one within the other, ecological studies are organized in hierarchical levels

b. In storing textiles, rugs, or other large-sized weavings, these should never be folded and piled one upon the other .

c. My grandmother had on not just one skirt, but four, one over the other.

There have of course been earlier approaches to these or related phenomena. The most relevant ones to our knowledge are the following: Moltmann (1995), who proposes an analysis of 'piece by piece' adverbials; Stockall (2001), who analyses 'dog after dog' type adverbials; and Zimmermann (2002), who proposes a refinement of Stockall's analysis. Our goal in this paper is not so much to develop a compositional semantics of (1), but rather to develop such an analysis in the framework of plural predication developed in Beck (2001). The earlier proposals just mentioned do not have that aim.

We will first introduce the background on plural predication that we assume, in section 2. In section 3 we analyse the 'one ... the other' type of adverbial in this system. We take a closer look at the internal make-up of the modifier in section 4 and propose a semantics we call pseudoreciprocal. We go on to suggest that a certain kind of apparent reciprocal had better receive an analysis in terms of pseudoreciprocity. Section 5 concludes the paper.

\section{Background}

Besides individuals (type $\left\langle\mathrm{e}>\right.$ ) we use eventualities (type $\langle\mathrm{v}\rangle$ ). We assume that both $\mathrm{D}_{\mathrm{e}}$ (the denotation domain of individuals - count and mass) and $\mathrm{D}_{\mathrm{V}}$ (the denotation domain of eventualities) have a mereological structure:

$$
\begin{aligned}
& \text { For any set } \mathrm{M} \subseteq \mathrm{D}_{\sigma}, \Sigma \mathrm{M} \in \mathrm{D}_{\sigma} \quad \text { (Lewis, 1991) } \\
& \text { where } \sigma=\mathrm{e} \text { or } \sigma=\mathrm{v} \text { and } \Sigma \mathrm{M} \text { is the mereological fusion of the elements of } \mathrm{M} \text {. } \\
& \mathrm{x}+\mathrm{y}=\Sigma\{\mathrm{x}, \mathrm{y}\} \\
& \text { the fusion of those individuals that are parts of } \mathrm{x} \text { or } \mathrm{y} \text { or overlap with } \mathrm{x} \text { and } \mathrm{y} \\
& \text { a. } \quad \text { part of relation } \leq \text { : } \\
& \text { b. } \quad \text { o primitive relation between individuals: antisymmetric, reflexive, transitive } \\
& \quad \mathrm{x} \text { o y iff } \exists \mathrm{z}[\mathrm{z} \leq \mathrm{x} \& \mathrm{z} \leq \mathrm{y}]
\end{aligned}
$$

We assume that basic predicates can be pluralized in order to apply to groups (or generally entities with a part-whole structure). For this purpose we use a family of operators of various types, beginning with Link's (1983) * operator for the pluralization of <e,t> predicates, and moving on to operators pluralizing relations (compare in particular Sternefeld (1998), also Beck (2001)). The relevant case for our present purposes is an operator $* *$ that pluralizes predicates of type $\langle\mathrm{e},\langle\mathrm{v}, \mathrm{t}\rangle\rangle$. The pluralized relation is true of all the things that the original relation was true of, plus all the part-whole structures that can be built from them.

Cumulation operator $* *$

Let $\mathrm{R}$ be a relation of type $\langle\mathrm{e},\langle\mathrm{v}, \mathrm{t}\rangle\rangle$. Then $\left[{ }^{* *} \mathbf{R}\right]$ is the smallest relation $\mathrm{R}$ ' such that the condtions in (a) and (b) are satisfied.

(a) $\quad \mathrm{R} \subseteq \mathrm{R}^{\prime}$

(b) for all $\langle x, e\rangle$ and $\left\langle y, e^{\prime}\right\rangle$ :

If $\langle\mathrm{x}, \mathrm{e}\rangle \in \mathrm{R}^{\prime}$ and $\left\langle\mathrm{y}, \mathrm{e}^{\prime}\right\rangle \in \mathrm{R}^{\prime}$, then $\left\langle\mathrm{x}+\mathrm{y}, \mathrm{e}+\mathrm{e}^{\prime}\right\rangle \in \mathrm{R}^{\prime}$

We further assume that all such pluralization is sensitive to a contextually given division of entities into subparts. We concretely follow Schwarzschild (1996) who suggests that the context provides a cover of the universe of discourse (compare also once more Moltmann (1995)). The covers relevant for our purposes will all be partitions (defined in (11a). (11b,c) 
define two useful bits of notation: the constraint that the cover be a partition of an entity $\mathrm{x}$ in (11b), and in (11c) the part of the cover that pertains to an entity $x$.

\section{(10) Cover (mereological version)}

$\mathrm{C}$ is a cover of $\mathrm{x}$ iff $\mathrm{C}$ is a set such that $\Sigma \mathrm{C}=\mathrm{x}$.

(11) a. A cover $\mathrm{C}$ is a partition iff for any $\mathrm{x}, \mathrm{y} \in \mathrm{C}: \mathrm{x}$ and $\mathrm{y}$ don't overlap.

b. $\quad \operatorname{PART}(\mathbf{C}, \mathbf{x}):=1$ iff $\mathrm{C}$ is a partition (and a cover) of $\mathrm{x}$.

c. $\quad \operatorname{Cov}[\mathrm{x}]=\{\mathrm{y}: \mathrm{y} \in \operatorname{Cov} \& \Sigma \mathrm{y} \leq \mathrm{x}\}$

We implement these suggestions through syntactic pluralization operations such as (12) for pluralization of type $\langle\mathrm{e},\langle\mathrm{v}, \mathrm{t}\rangle\rangle$ predicates; (12) combines the $* *$ operator with the requirement that the division into subparts be into the contextually relevant ones, plus the presupposition that the contextually provided cover be a partition of the entities considered.

$$
\begin{aligned}
{[[\mathbf{P L}]]=} & \lambda \operatorname{Cov} \cdot \lambda \mathrm{R}<\mathrm{e},\langle\mathrm{v}, \mathrm{t}>>\cdot \lambda \mathrm{x} \cdot \lambda \mathrm{e}: \operatorname{PART}(\operatorname{Cov}, \mathrm{e}+\mathrm{x}) . \\
& * *\left[\lambda \mathrm{x}^{\prime} \cdot \lambda \mathrm{e}^{\prime} \cdot \operatorname{Cov}\left(\mathrm{e}^{\prime}\right) \& \operatorname{Cov}\left(\mathrm{x}^{\prime}\right) \& \mathrm{R}\left(\mathrm{x}^{\prime}\right)\left(\mathrm{e}^{\prime}\right)\right](\mathrm{x})(\mathrm{e})
\end{aligned}
$$

The use of PL is illustrated in the example in (13). A predicate of type $\langle\mathrm{e},\langle\mathrm{v}, \mathrm{t}\rangle\rangle$ is created through movement of the object NP. The PL operator together with its cover restriction is adjoined to that predicate. If the presupposition triggered by PL is met, the result will be the predicate of events in (13c). (13c) is true of an event e iff e and the cake can be divided into relevant parts $\mathrm{x}$ and $\mathrm{e}$ ' that stand in the relation 'John ate $\mathrm{x}$ in $\mathrm{e}$ ". The cake and the big event $\mathrm{e}$ can be divided in this way just in case (13d) is true: each relevant part of the cake was eaten by John in a relevant subevent, and each relevant subevent has John eating a relevant part of the cake in it. Thus (13a) is true of an event that can be divided into smaller events of eating parts of the cake; a sample situation would be (14).

(13) a. John ate the cake.

b. [ [the cake] [PLCov $[\langle\mathrm{e},\langle\mathrm{v}, \mathrm{t}\rangle\rangle \lambda 1[\mathrm{John}$ ate $\mathrm{t} 1]]]]$

c. $\quad \lambda \mathrm{e} .\langle\mathrm{e}, \mathrm{C}\rangle \in * *\left[\lambda \mathrm{x} \cdot \lambda \mathrm{e}^{\prime} \cdot \operatorname{Cov}(\mathrm{x}) \& \operatorname{Cov}\left(\mathrm{e}^{\prime}\right) \& \mathrm{~J}\right.$ eat $\mathrm{x}$ in $\left.\mathrm{e}^{\prime}\right]$

d. $\forall \mathrm{x}\left[\mathrm{x} \leq \mathrm{C} \& \operatorname{Cov}(\mathrm{x})->\exists \mathrm{e}^{\prime}\left[\mathrm{e}^{\prime} \leq \mathrm{e} \& \operatorname{Cov}\left(\mathrm{e}^{\prime}\right) \& \mathrm{~J}\right.\right.$ eat $\mathrm{x}$ in $\left.\left.\mathrm{e}^{\prime}\right]\right] \&$ $\forall \mathrm{e}^{\prime}\left[\mathrm{e}^{\prime} \leq \mathrm{e} \& \operatorname{Cov}\left(\mathrm{e}^{\prime}\right)->\exists \mathrm{x}\left[\mathrm{x} \leq \mathrm{C} \& \operatorname{Cov}(\mathrm{x}) \& \mathrm{~J}\right.\right.$ eat $\mathrm{x}$ in $\left.\left.\mathrm{e}^{\prime}\right]\right]$

(14) a. $\mathrm{g}(\mathrm{Cov})[\mathrm{C}+\mathrm{e}]=\{\mathrm{c} 1, \mathrm{c} 2, \mathrm{e} 1, \mathrm{e} 2\}$ with $\mathrm{e}=\mathrm{e} 1+\mathrm{e} 2$ and $\mathrm{C}=\mathrm{c} 1+\mathrm{c} 2$

b. $\quad \llbracket$ eat $\rrbracket=\{\langle\mathrm{J}, \mathrm{c} 1, \mathrm{e} 1\rangle,\langle\mathrm{J}, \mathrm{c} 2, \mathrm{e} 2\rangle\}$

It is not obvious that such an analysis in terms of pluractionality is needed for (13). In (15), however, with the adverbial 'piece by piece', it is clear that the truth conditions of the sentence imply a division of the overall event of eating the cake into subevents depending on a division of the cake into pieces. This is reflected in the truth conditions described in (15'). The adverbial 'piece by piece' seems to be an instantiation of a version of the PL operator with a cover of the cake into pieces. We will not worry here too much about how to implement this idea; one possibility is given in (16). The resulting truth conditions (16c) correspond closely to the ones in (13c,d): (16c) is true of an event e iff e and the cake can be divided into relevant parts $y^{\prime}$ and e' such that $y^{\prime}$ is a piece and John are $y^{\prime}$ in e'. That is, each piece of the cake was eaten by John in some relevant subevent, and each relevant subevent was John eating a piece of the cake.

(15) John ate the cake piece by piece.

$\left(15^{\circ}\right)(15)$ is true of an event e iff the relevant division of the cake is into pieces, and each piece was eaten by John in a relevant subevent of e, and each relevant subevent of e is an eating of one of the pieces by John. 
(16) a. [ [the cake] [ piece by pieceCov $[\langle\mathrm{e},\langle\mathrm{v}, \mathrm{t}\rangle\rangle\rangle 2[\mathrm{John}$ ate $\mathrm{t} 2]]]]$

b. $\quad[[$ piece by pieceCov $]]=\lambda \mathrm{R}<\mathrm{e}<\mathrm{v}, \mathrm{t}>>. \lambda \mathrm{y} . \lambda \mathrm{e}$ : $\operatorname{PART}(\operatorname{Cov}, \mathrm{e}+\mathrm{y})$.

$* *\left[\lambda \mathrm{y}^{\prime} . \lambda \mathrm{e}^{\prime} . \operatorname{Cov}\left(\mathrm{y}^{\prime}\right) \& \operatorname{Cov}\left(\mathrm{e}^{\prime}\right) \& \mathrm{y}^{\prime}\right.$ is a piece $\left.\& \mathrm{R}\left(\mathrm{y}^{\prime}\right)\left(\mathrm{e}^{\prime}\right)\right](\mathrm{y})(\mathrm{e})$

c. $\quad \lambda$ e. $\left\langle e, C>\in * *\left[\lambda y^{\prime} . \lambda e^{\prime} . \operatorname{Cov}\left(y^{\prime}\right) \& \operatorname{Cov}\left(e^{\prime}\right) \& y^{\prime}\right.\right.$ is a piece $\&$ John ate $y^{\prime}$ in $\left.e^{\prime}\right]$

\section{One after the Other}

We can now return to the problem that interests us, repeated below. We approach it by first considering more standard occurrences of the modifier 'after NP' and extending their analysis to 'after the other'.

(2) These three dogs entered the room one after the other.

D3 -> D2 -> D1

(3) These three dogs entered the room, and the entering can be divided into a sequence of subevents in each of which one of the dogs enters, and the dogs can be divided into a sequence of individual dogs each of which entered in one of the subevents.

\subsection{The Modifier 'after NP'}

Our baseline will be the contribution of 'after NP' suggested in (17') for (17). This leads to the semantics in (17") for 'after Katie': it modifies a relation of type $\langle\mathrm{e},\langle\mathrm{v}, \mathrm{t}\rangle\rangle$ and adds the information that the relation held between Katie and the immediately preceding event. We rely on the notion of the relevant predecessor of an event, which is the event whose running time is immediately before the running time of the event considered.

(17) Min entered the room (immediately) after Katie.

$\left(17^{`}\right) \lambda$ e. Min enters the room in e \& Katie enters the room in pred(e)

$\operatorname{pred}(\mathrm{e})$ : the immediate predecessor of $\mathrm{e}$

$\left(17^{*}\right) \quad[[$ after Katie $]]=\lambda \mathrm{R}<\mathrm{e},\langle\mathrm{v}, \mathrm{t}>>. \lambda x . \lambda \mathrm{e} . \mathrm{R}(\mathrm{x})(\mathrm{e}) \& \mathrm{R}(\operatorname{Katie})(\operatorname{pred}(\mathrm{e}))$

$$
\operatorname{pred}(\mathrm{e})=1 \mathrm{e}^{\prime}: \tau\left(\mathrm{e}^{\prime}\right)<\tau(\mathrm{e}) \& \forall \mathrm{e}^{\prime \prime}\left[\tau\left(\mathrm{e}^{\prime \prime}\right)<\tau(\mathrm{e})->\mathrm{e}^{\prime \prime}=\mathrm{e}^{\prime} \text { or } \tau\left(\mathrm{e}^{\prime \prime}\right)<\tau\left(\mathrm{e}^{\prime}\right)\right]
$$

A generalized verison of this idea is given in (19) and (20). There is an ordering relation on events based on temporal precedence. We can identify the predecessor according to that order.

(19) ordering relation on events:

e is before $\mathrm{e}^{\prime}: \quad \quad \mathrm{e} \angle \mathrm{e}^{\prime}$ iff $\tau(\mathrm{e})<\tau\left(\mathrm{e}^{\prime}\right)$

(20) the immediate predecessor of $\mathrm{e}$ :

$\operatorname{pred}(\mathrm{e})=\mathrm{ee}^{\prime}: \mathrm{e}^{\prime} \angle \mathrm{e} \& \forall \mathrm{e}^{\prime \prime}\left[\mathrm{e}^{\prime \prime} \angle \mathrm{e}->\mathrm{e}^{\prime \prime}=\mathrm{e}^{\prime}\right.$ or e" $\left.\angle \mathrm{e}^{\prime}\right]$

\subsection{The 'Other' Dog}

The instance of the 'after'-modifier that we are confronted with is 'after the other'. The key to our analysis of pluractional 'one after the other' lies in our understanding of the meaning of 'the other' in this construction. We suggest that for each dog, the relevant other dog is always the immediately preceding one. That is, we propose that there is an ordering on the individuals that is derived from the ordering of events, as in (21). The predecessor of an individual can be defined on the basis of that derived order. 
(21) ordering relation on individuals:

$\mathrm{x} \angle \mathrm{y}$ iff $\exists \mathrm{e}\left[\mathrm{x}\right.$ is in e and $\forall \mathrm{e}^{\prime}\left[\mathrm{y}\right.$ is in $\left.\left.\mathrm{e}^{\prime}->\mathrm{e} \angle \mathrm{e}^{\prime}\right]\right]$

$\mathrm{x}$ is before $\mathrm{y}$ iff $\mathrm{x}$ occurs in a relevant event before $\mathrm{y}$ does

(22) the immediate predecessor of $x$ :

$\operatorname{pred}(\mathrm{x})=\mathrm{ty}: \mathrm{y} \angle \mathrm{x} \& \forall \mathrm{z}[\mathrm{z} \angle \mathrm{x}->\mathrm{z}=\mathrm{y}$ or $\mathrm{z} \angle \mathrm{y}]$

Finding the predecessor for each dog requires that the dogs can successfully be ordered into a sequence. (23) defines the notion of sequence: the cover has to have this property so that its members can be ordered. In our example, we would have (24).

(23) $\operatorname{Cov}[x]$ is a sequence iff

$\operatorname{Cov}[\mathrm{x}]=\left\{\mathrm{x}_{1}, \ldots, \mathrm{x}_{\mathrm{n}}\right\}$ and for any $\mathrm{x}_{\mathrm{i}}, \mathrm{x}_{\mathrm{i}+1}: \mathrm{x}_{\mathrm{i}} \angle \mathrm{x}_{\mathrm{i}+1}$

$\operatorname{Cov}[\mathrm{e}]=\left\{\mathrm{e}_{1}, \ldots, \mathrm{e}_{\mathrm{n}}\right\}$ such that for any $\mathrm{e}_{\mathrm{i}}, \mathrm{e}_{\mathrm{i}+1}$ : $\mathrm{e}_{\mathrm{i}} \angle \mathrm{e}_{\mathrm{i}+1}$

$\operatorname{Cov}[$ these $3 \mathrm{dogs}]=\left\{\mathrm{x}_{1}, \ldots, \mathrm{x}_{\mathrm{n}}\right\}$ such that for any $\mathrm{x}_{\mathrm{i}}, \mathrm{x}_{\mathrm{i}+1} \mathrm{x}_{\mathrm{i}} \angle \mathrm{x}_{\mathrm{i}+1}:=\{\mathrm{D} 1, \mathrm{D} 2, \mathrm{D} 3\}$

If the appropriate sequence is given, then the truth conditions of our example (1) can be stated as in (25) below. From (25a) we get (25b). The overall truth conditions we propose are paraphrased in (26).

(25) a. $\quad<3 \mathrm{D}, \mathrm{e}>\in^{* *}\left[\lambda \mathrm{x} \cdot \lambda \mathrm{e}^{\prime} . \operatorname{Cov}(\mathrm{x}) \& \operatorname{Cov}\left(\mathrm{e}^{\prime}\right) \& \mathrm{x}\right.$ enters the room in $\mathrm{e}^{\prime} \&$ $\operatorname{pred}(\mathrm{x})$ enters the room in $\left.\operatorname{pred}\left(\mathrm{e}^{\prime}\right)\right]$

b. $\quad \forall \mathrm{x}\left[\mathrm{x} \leq 3 \mathrm{D} \& \operatorname{Cov}(\mathrm{x})->\exists \mathrm{e}^{\prime}\left[\mathrm{e}^{\prime} \leq \mathrm{e} \& \operatorname{Cov}\left(\mathrm{e}^{\mathrm{c}}\right) \& \mathrm{x}\right.\right.$ enters the room in $\mathrm{e}^{\prime} \&$ $\operatorname{pred}(\mathrm{x})$ enters the room in $\left.\left.\operatorname{pred}\left(\mathrm{e}^{\prime}\right)\right]\right] \&$

$\forall \mathrm{e}^{\prime}\left[\mathrm{e}^{\prime} \leq \mathrm{e} \& \operatorname{Cov}\left(\mathrm{e}^{\prime}\right)->\exists \mathrm{x}\left[\mathrm{x} \leq 3 \mathrm{D} \& \operatorname{Cov}(\mathrm{x}) \& \mathrm{x}\right.\right.$ enters the room in $\mathrm{e}^{\prime} \&$ $\operatorname{pred}(\mathrm{x})$ enters the room in $\left.\left.\operatorname{pred}\left(\mathrm{e}^{\prime}\right)\right]\right]$

(26) e can be divided into a sequence of subevents, and

the three dogs can be divided into a sequence of individual dogs, such that

each dog entered the room in a relevant subevent, and its predecessor entered in the preceding subevent, and

each subevent was one of one of the dogs entering, and the preceding event was one of the predecessor of that dog entering.

These truth conditions can be derived straightforwardly from the Logical Form in (27). The subject is raised, with the movement binding an anaphor contained in the NP 'the other'; the relevant pluralization operator is attached to the modified relation (the predicate created by the movement). We propose a version of our PL operator that incorporates the constraint on the cover that the cover of the relevant entity and event be a sequence. And we suggest a semantics for the modfier 'one after the other' that is essentially a combination of what we found out about 'after NP' in (17") and the idea that the NP here contributes, for each dog, the predecessor of that dog. With this, (27) will give rise to the truth conditions in (26).

(27) these 3 dogs $\left[\mathrm{PL}^{\mathrm{seq}} \mathrm{Cov} \lambda \mathrm{x}[\langle\mathrm{v}, \mathrm{t}\rangle \mathrm{x}[\langle\mathrm{e},\langle\mathrm{v}, \mathrm{t}\rangle\rangle\right.$ entered the room] [one after the other $\left.\mathrm{x}]]\right]$

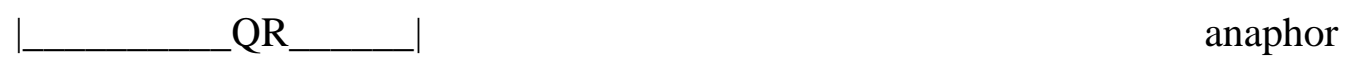

(28) $\llbracket$ one after the other $\mathrm{x} \rrbracket^{\mathrm{g}}=\lambda \mathrm{R} \cdot \lambda \mathrm{y} \cdot \lambda \mathrm{e} \cdot \mathrm{R}(\mathrm{y})(\mathrm{e}) \& \mathrm{R}(\operatorname{pred}(\mathrm{g}(\mathrm{x})))(\operatorname{pred}(\mathrm{e}))$

(29) $\quad\left[\left[\mathbf{P L}^{\mathbf{S e q}} \mathbf{C o v}\right]\right]=\lambda \mathrm{R} \cdot \lambda z \cdot \lambda \mathrm{e} \cdot \operatorname{Cov}[\mathrm{e}]$ is a sequence and $\operatorname{Cov}[\mathrm{z}]$ is a sequence $\&$

$$
* *\left[\lambda z^{\prime} . \lambda e^{\prime} . \operatorname{Cov}\left(z^{\prime}\right) \& \operatorname{Cov}\left(e^{\prime}\right) \& R\left(z^{\prime}\right)\left(e^{\prime}\right)\right](z)(e)
$$




\subsection{The First Dog}

The observant reader will no doubt have noticed that the truth conditions in (26) suffer from a problem: We require that for each dog, that dog enter after its predecessor. But the first dog in the sequence does not have a predecessor. So (26) as such could never be true.

We propose to embrace this prediction - so our compositional semantics will derive these truth conditions. There must then be a pragmatic process that allows us to ignore the first dog, and thus makes it possible for (26) to be true. We suggest that essentially the same process is at work in (30) and (31) below. In (31) for instance, we must subtract Arnim from the domain of quantification and understand 'everyone' to mean here 'everyone but Arnim'; else the sentence could never be true. Likewise we subtract the first sentry in the row from the domain that 'each' quantifies over.

(30) 20 Wachposten sind so in einer Reihe aufgestellt, dass jeder den vorherigen sehen kann.

20 sentries are standing in a row such that each can see the one before him.

(31) Everyone has a faster computer than Arnim.

Thus we think that it is generally possible to reinterpret a quantificational statement that could not come out true by subtracting the problematic indivdual from the domain of quantification. This process will also have to apply to our examples in (1).

\subsection{Similar Cases: One above/within the Other}

In this subsection, we indicate how the analysis proposed for 'one after the other' extends to similar instances of pluractional adverbials with different prepositions. Some examples are given below. We will focus on (32a) with 'above'.

(32) a. These three children sleep one above/ next to the other.

b. She laid the books bundle beside/ upon bundle on the porch.

Our starting point is once more a regular occurrence of the modifier, (33a). The semantics in (33b) leads to the meaning in (34) for the modifier. Like our earlier example 'after NP', the PP modifies a relation. In this case, this is a relation between an individual and a place. It adds to the original relation the information that the relation also holds between the referent of the NP and the relevant preceding place, which is the place immediately below.

(33) a. Hans sleeps above Fritz.

b. $\quad \lambda$ p. Hans sleeps at $\mathrm{p} \&$ Fritz sleeps at bel(p)

$\operatorname{bel}(\mathrm{p})=$ the place immediately below $\mathrm{p}$

$$
[[\text { above Fritz] }]=\lambda R \cdot \lambda x \cdot \lambda p . R(x)(p) \& R(\text { Fritz })(\operatorname{bel}(p))
$$

Once more, then, we have an ordering relation, this time based on the meaning of the preposition 'above'. A place is smaller than another one according to that ordering if it is below it. We then also have the notion of the immediately preceding place.

\section{ordering relation on places:}

$\mathrm{p} \angle \mathrm{p}^{\prime}$ iff $\mathrm{p}$ is below $\mathrm{p}^{\prime}$

$$
\begin{aligned}
& \text { the immediate predecessor of p: } \\
& \operatorname{bel}(\mathbf{p})=\mathrm{t} \mathrm{p}^{\prime}: \mathrm{p}^{\prime} \angle \mathrm{p} \& \forall \mathrm{p}^{\prime \prime}\left[\mathrm{p}^{\prime \prime} \angle \mathrm{p}->\mathrm{p}^{\prime \prime}=\mathrm{p}^{\prime} \text { or } \mathrm{p}^{\prime \prime} \angle \mathrm{p}^{\prime}\right]
\end{aligned}
$$

In order to find a denotation for the NP 'the other' in the pluractional adverbial 'one above the other', we again suppose that there is a derived ordering of individuals based on the one of places (as defined in (37)), which will permit us to define the predecessor of an individual according to the scale introduced by 'above' (cf. (38)). 
(37) ordering relation on individuals:

$\mathrm{x} \angle \mathrm{y}$ iff $\exists \mathrm{p}[\mathrm{x}$ is in $\mathrm{p}$ and $\forall \mathrm{p} "[\mathrm{y}$ is in $\mathrm{p} "->\mathrm{p} \angle \mathrm{p} "]]$

$\mathrm{x}$ is below $\mathrm{y}$ iff $\mathrm{x}$ is in a place that is below any place that $\mathrm{y}$ is in.

$$
\begin{aligned}
& \text { the immediate predecessor of } \mathbf{x} \\
& \operatorname{bel}(\mathbf{x})=\mathrm{ty}: \mathrm{y} \angle \mathrm{x} \& \forall \mathrm{z}[\mathrm{z} \angle \mathrm{x}->\mathrm{z}=\mathrm{y} \text { or } \mathrm{z} \angle \mathrm{y}]
\end{aligned}
$$

The rest of the analysis is quite parallel to the analysis of the 'after' example. We must be able to divide both the place and the plural individual into a sequence. Given that, we propose the analysis in terms of the ** in (40) which amounts to the truth conditions in (41). The resulting truth conditions are described roughly in (42).

\section{$\operatorname{Cov}[\mathrm{p}]=\left\{\mathrm{p}_{1}, \ldots, \mathrm{p}_{\mathrm{n}}\right\}$ such that for any $\mathrm{p}_{\mathrm{i}}, \mathrm{p}_{\mathrm{i}+1}: \mathrm{p}_{\mathrm{i}} \angle \mathrm{p}_{\mathrm{i}+1}$}

$\operatorname{Cov}[$ these 3 children $]=\left\{\mathrm{x}_{1}, \ldots, \mathrm{x}_{\mathrm{n}}\right\}$ such that for any $\mathrm{x}_{\mathrm{i}}, \mathrm{x}_{\mathrm{i}+1}: \mathrm{x}_{\mathrm{i}} \angle \mathrm{x}_{\mathrm{i}+1}$

$$
\begin{aligned}
& \langle 3 \mathrm{C}, \mathrm{p}\rangle \in * *\left[\lambda \mathrm{x} . \lambda \mathrm{p}^{\prime} . \operatorname{Cov}(\mathrm{x}) \& \operatorname{Cov}\left(\mathrm{p}^{\prime}\right) \& \mathrm{x} \text { sleeps in } \mathrm{p}^{\prime} \& \operatorname{bel}(\mathrm{x}) \text { sleeps in bel}\left(\mathrm{p}^{\prime}\right)\right] \\
& \forall \mathrm{x}[\mathrm{x} \leq 3 \mathrm{C} \& \operatorname{Cov}(\mathrm{x})-> \\
& \left.\left.\exists \mathrm{p}^{\prime}\left[\mathrm{p}^{\prime} \leq \mathrm{p} \& \operatorname{Cov}\left(\mathrm{p}^{\prime}\right) \& \mathrm{x} \text { sleeps in } \mathrm{p}^{\prime} \& \operatorname{bel}(\mathrm{x}) \text { sleeps in bel( } \mathrm{p}^{\prime}\right)\right]\right] \text { \& } \\
& \forall \mathrm{p}^{\prime}\left[\mathrm{p}^{\prime} \leq \mathrm{p} \& \operatorname{Cov}\left(\mathrm{p}^{\prime}\right)->\right. \\
& \left.\left.\exists x\left[x \leq 3 C \& \operatorname{Cov}(x) \& x \text { sleeps in } \mathrm{p}^{\prime} \& \operatorname{bel}(\mathrm{x}) \text { sleeps in bel( } \mathrm{p}^{\prime}\right)\right]\right]
\end{aligned}
$$

(42) The place $\mathrm{p}$ can be divided into a sequence of subplaces,

and the three children can be divided into a sequence of individual children such that:

each child sleeps above the one immediately below,

and each place has a child sleeping in it (...).

The compositonal derivation of these truth conditions is based on the Logical Form in (43) and uses the PL operator in (44) - the same one as before adapted to talk about places instead of events.

(43) these 3 children [PL ${ }^{\text {seq }} \operatorname{Cov} \lambda x[\mathrm{x}[[$ sleep] [one above the other $\mathrm{x}]]]$

(44) $\quad\left[\left[\mathbf{P L}^{\mathbf{S e q}} \mathbf{C o v}\right]\right]=\lambda R \cdot \lambda z \cdot \lambda p . \operatorname{Cov}[\mathrm{p}]$ is a sequence and $\operatorname{Cov}[\mathrm{z}]$ is a sequence $\&$

$$
* *\left[\lambda z^{\prime} . \lambda p^{\prime} \cdot \operatorname{Cov}\left(z^{\prime}\right) \& \operatorname{Cov}\left(p^{\prime}\right) \& R\left(z^{\prime}\right)\left(p^{\prime}\right)\right](z)(p)
$$

Other prepositions occuring in the structure 'one Preposition the other' would give rise to different orderings, but be otherwise parallel to the examples discussed.

\section{Pseudoreciprocity}

In this section we will take a closer look at the internal structure of the modifier 'one...the other' and propose a more detailed analysis. We then extend that analysis to certain cases of apparent reciprocals, namely Dalrymple et al.'s (1998) Inclusive Alternative Ordering reciprocals.

\subsection{Pseudoreciprocal 'One ... the Other'}

The overt material in (45a) suggests an internal structure of the modifier as in (45b). We assume that in addition there is covert structure in the form of the anaphor $\mathrm{x}$ and $\mathrm{a}$ contextually given relation that will constrain us to the relevant other individual. A hidden anaphor in the expression 'other' has been suggested e.g.in Heim et al. (1991) on the basis of data like (46): 'another' here means 'a shirt different from this shirt'. The expression 'another' 
thus includes an anaphoric reference to 'this shirt'. The difference between (46) and our data (as well as reciprocal pronouns) is that the anaphor is bound in the latter case.

(45) a. The dogs entered the room one after the other.

b. [one [ after [ the [other]]]]

c. [one [ after [ the [ R other $\mathrm{x}]]]]$

(46) I don't like this shirt, bring me another.

In (47) we recall the desired semantics for 'the other', argued for in the previous section. We can achieve this result if the hidden relation variable is assigned by the context the value in (48a) (this must come from the preposition), and compositional interpretation proceeds as in (48b). We end up with the meaning 'that $\mathrm{y}$ which is not $\mathrm{x}$ and immediately preceeds $\mathrm{x}$ ' - the predecessor of $\mathrm{x}$ according to the 'after' relation.

$$
\begin{aligned}
\mathbb{I} \text { the } \mathrm{R} \text { other } \mathrm{x}]^{\mathrm{g}} & =\operatorname{pred}(\mathrm{g}(\mathrm{x})) \\
& =\mathrm{ty}: \mathrm{y} \text { immediately precedes } \mathrm{g}(\mathrm{x}) \\
& =\mathrm{ty}: \mathrm{y} \angle \mathrm{g}(\mathrm{x}) \& \forall \mathrm{z}[\mathrm{z} \angle \mathrm{g}(\mathrm{x})->\mathrm{z}=\mathrm{y} \text { or } \mathrm{z} \angle \mathrm{y}]
\end{aligned}
$$

(48) a. $\mathrm{g}(\mathrm{R})=$ immediately precede

b. $\quad[[$ the $[N P<e, t>[<e,<e, t>>R$ other $] \mathrm{x}]]]]^{\mathrm{g}}$

$$
=\text { ty: } \mathrm{y} \neq \mathrm{g}(\mathrm{x}) \& \mathrm{~g}(\mathrm{R})(\mathrm{g}(\mathrm{x}))(\mathrm{y})=\operatorname{pred}(\mathrm{g}(\mathrm{x}))
$$

The referential NP needs to combine with 'after' in the same way as the referential NP 'Katie' would in the simpler case, repeated in (49). The 'after' from (50b) is combined with the meaning of 'the other' in (51). The actual modifier we see also includes 'one'. We propose that that provides an additional constraint on the individual argument of the relation, namely that that be a singular individual. The meaning of 'one after the other' is then as in (52).

(49) a. Min entered the room after Katie.

b. $\quad \lambda$ e. Min enters the room in e \& Katie enters the room in pred(e)

(50) a. $\quad \llbracket$ after Katie $\rrbracket=\lambda P . \lambda x . \lambda e . P(x)(e) \& P(K a t i e)(\operatorname{pred}(e))$

b. $\quad \llbracket$ after $\rrbracket=\lambda z . \lambda P . \lambda x . \lambda e . P(x)(e) \& P(z)(\operatorname{pred}(e))$

(51) $\quad \llbracket$ after the $\mathrm{R}$ other $\mathrm{x} \rrbracket \mathrm{g}=\lambda \mathrm{P} . \lambda \mathrm{y} . \lambda \mathrm{e} . \mathrm{P}(\mathrm{y})(\mathrm{e}) \& \mathrm{P}(\operatorname{pred}(\mathrm{g}(\mathrm{x})))(\operatorname{pred}(\mathrm{e}))$

(52) $\llbracket$ one after the R other $\mathrm{x} \rrbracket \mathrm{g}=\lambda \mathrm{P} \cdot \lambda \mathrm{y} \cdot \lambda \mathrm{e} \cdot \mathrm{P}(\mathrm{y})(\mathrm{e}) \&$ one $(\mathrm{y}) \& \mathrm{P}(\operatorname{pred}(\mathrm{g}(\mathrm{x})))(\operatorname{pred}(\mathrm{e}))$

We believe that $(53 a, b)$ are equivalent. Hence we suggest that the two modifiers make the same semantic contribution. One way to derive this would be to have an underlying form (54a) from which both are derived as different surface forms.

(53) a. She washed them dog after dog.

b. She washed them one (dog) after the other.

(54) a. one dog after the other dog

b. one dog after the other dog

c. ene dog after dog

It is relatively obvious how to derive 'one after the other' from (54a), namely, through a process of $\mathrm{N}$-deletion. This is not obligatory, at least not for the first $\mathrm{N}$ to be deleted, cf. (55). (It is far less obvious how (54c) would be derived, and in fact some issues remain open regarding the internal structure that might suggest that one would not always trace reduplicative adverbials to the same source as 'one ... the other' adverbials. We will put this aside for the moment.) 
(55) a. She put the books one bundle beside the other (bundle) on the porch.

b. She examined the wine one bottle after the other (bottle).

The above considerations lead to a final revision for the internal semantics of the modifier which yields (56): we add the information that the relevant predecessor as well as the individual argument of the relation are Ns.

a. $\quad$ II [the $[[[\mathrm{R}$ other $] \mathrm{x}] \mathrm{N}]]]^{\mathrm{g}}=$ ly: $\mathrm{y} \neq \mathrm{g}(\mathrm{x}) \& \mathrm{~g}(\mathrm{R})(\mathrm{g}(\mathrm{x}))(\mathrm{y}) \& \mathbb{\mathbb { N }} \rrbracket(\mathrm{y})=\operatorname{pred}(\mathrm{g}(\mathrm{x}))$

b. $\quad[$ one $\mathrm{N}$ after [the $\mathrm{R}$ other $\mathrm{x} \mathrm{N}] \rrbracket \mathrm{g}=$ $\lambda P . \lambda y . \lambda e . P(y)(e) \&$ one $(y) \& \llbracket N \rrbracket(y) \& P(\operatorname{pred}(\mathrm{g}(\mathrm{x})))(\operatorname{pred}(\mathrm{e}))$

We call these modifiers pseudoreciprocal. They are reminiscent of reciprocals formally in the use of 'other', and semantically in talking about a different member of the same group. But they are not reciprocal pronouns formally. Moreover, the NP in the modifier is a singular. By contrast, a reciprocal pronoun introduces a second plurality of individuals (Beck (2001)).

\subsection{IAO Reciprocals as Pseudoreciprocals}

Finally, we will explore the possibility of extending our analysis of pseudoreciprocals to certain apparent reciprocals, namely those that have an Inclusive Alternative Odering (IAO) interpretation. Some examples of such reciprocals are given in (57). The interpretation of (57a) according to Dalrymple et al. is paraphrased in (58). The general schema of an IAO interpretation is given in (59). The data in (57) are all taken to have such a weak semantics.

(57) a. The children sleep above each other.

b. The three dogs came into the room after one another /

The three dogs followed each other into the room.

(58) IAO: Each child sleeps above or below some other child.

(59) a. Schema of an elementary reciprocal sentence:

$\begin{array}{lll}\text { A } & \mathrm{R} & \text { each other. } \\ \text { antecedent } & \text { relation } & \text { reciprocal pronoun }\end{array}$

b. IAO: $\forall \mathrm{x}[\mathrm{x} \leq \mathrm{A}->\exists \mathrm{y}[\mathrm{y} \leq \mathrm{A} \& \mathrm{xRy}$ or $\mathrm{yRx}]]$

We suggest instead that the data in (57) (and IAO reciprocals in general) have a pseudoreciprocal semantics. That is, (57a) really amounts to (60a). The semantics we assign to (60a), and by assumption then also to (57a), entails (60b).

(60) a. The children sleep one above the other.

b. $\quad$ Each child sleeps above some other child

(namely, her "predecessor" relative to the 'below'- relation).

Why do we pursue this idea? There are three kinds of facts that motivate us. The first is that the IAO truth conditions are very weak indeed, and intuitively too weak for example for (57b). The IAO truth conditions for (57b) are given in (61a). These truth conditions predict the sentence to be true in the situation depicted in (61b). This doesn't accord with intuitions. By contrast, our truth conditions will render (57b) equivalent to (61c) and correctly predict that the sentence is false in a situation like (61b).

(61) a. Each dog came into the room after or before some other dog.

b. D3+D2 $\rightarrow$ D1

c. The dogs entered the room one after the other. 
A second problem for IAO reciprocals is the fact that an IAO interpretation is only possible with a restricted set of relations. See Beck (2001) and references therein for discussion. As an illustration, notice that (62a) with the relation 'on top of' is acceptable under an IAO interpretation while (62b) with 'outnumber' is unacceptable and cannot have an IAO reading (which would be made true by the fact that the Smiths are more numerous than the Johnsons, for instance). If IAO were a regular interpretation for reciprocal sentences, why should it not be generally available?

(62) a. The plates are stacked on top of each other.

b. * The Smiths and the Johnsons outnumber each other.

A third and final problem with IAO is noted in Beck (2001): IAO reciprocals are restricted to local reciprocal relations while other reciprocals are not. To illustrate what is meant by a nonlocal reciprocal relation, consider (63). The sentence is judged true if (63'a) is the case. This can be derived from the truth conditions in $\left(63^{\prime} \mathrm{b}\right)$ : the reciprocal relation 'want to kill' holds between non-identical members of the antecedent group 'Tracy and Joe'. (63) is an example of a regular reciprocal interpretation, weak reciprocity. The reciprocal relation 'want to kill' is non-local in that it is not a relation that exists as the meaning of a surface constituent.

(63) Tracy and Joe want to kill each other.

(63') a. Tracy wants to kill Joe and Joe wants to kill Tracy.

b. $\quad\langle\mathrm{T} \& \mathrm{~J}, \mathrm{~T} \& \mathrm{~J}>\in * * \lambda \mathrm{x} \lambda \mathrm{y}: \mathrm{x} \neq \mathrm{y}$. $\mathrm{x}$ wants to kill $\mathrm{y}]$

We should contrast (63) with (64). The sentence can be understood as in (65) - Tracy and Joe agree that they want to sleep above each other rather than, say, beside each other. It cannot be understood as in (66), which would be made true by the fact that Tracy wants to sleep above Joe. (66) would be a non-local IAO interpretation with the reciprocal relation 'want to sleep above'. Clearly, this is not possible. Only a local reading inside the embedded clause in (65) is acceptable.

(64) Tracy and Joe want to sleep above each other.

(65) Tracy and Joe both have the following desire: we sleep above each other.

(66) For each $x, x$ one of Tracy and Joe: either $x$ wants to sleep above the other one of Tracy and Joe, or the other one of Tracy and Joe wants to sleep above $\mathrm{x}$.

The pair in (67) makes the same point: in (67a) a non-local interpretation is possible in which the different members of the antecedent group 'these people' were introduced by different linguists. A similar interpretation is not available in (67b); the same apprentice magician has to line up the glasses.

(67) a. These people were introduced to each other by a linguist.

b. The glasses were lined up behind each other by an apprentice magician.

The two constraints on the availability of IAO interpretations (limited set of relations, and local interpretation only) are quite unexpected as long as one thinks of IAO as a regularly available interpretation of reciprocal pronouns. This is additional motivation then, besides the problem mentioned above with inappropriately weak truth conditions, for looking for an alternative analysis of the phenomenon of IAO. We propose that IAO reciprocals only appear to be reciprocals, and are really pseudoreciprocals:

(68) above each other $==>$ (one) above the other

That is, the example in (69a) should really be interpreted as (69b). 
(69) a. Tracy and Joe want to sleep above each other.

b. Tracy and Joe want to sleep one above the other.

The truth conditions we predict are the ones of pseudoreciprocals, which seems right to us. As for the unexpected constraints on the relations that participate in an IAO interpretation, we have nothing concrete to offer. One may suppose that whatever process relates (69a) and (69b) is somehow restricted and cannot apply to every relation. For all we know, the connection may be lexical. But no concrete predictions arise regarding which relations can participate.

We do have something to say about the fact that apparent IAO reciprocals - now reanalysed as pseudoreciprocals - only receive a local interpretation. In $(64)=(69)$, for instance, the whole '(one) above the other' is an adverbial that can only modify the embedded predicate 'sleep' (whishes cannot plausibly be above each other). And since there is no further potentially scope bearing element in this modifier ('the other' being a singular), there is no process that could generate a non-local interpretation.

A final comment: there are cases of IAO reciprocals for which our pseudoreciprocal truth conditions might be thought too strong. (70b) is a case in point. Dalrymple et al. point out that such a sentence can be considered true in a situation with two bunk beds each of which sleeps two children. This is different from (70a), our pseudoreciprocal. We speculate that (70b) permits a partition of the children into two groups of two, on which its interpretation with the bunk beds is based. This is excluded by the overt element 'one' in (70a) which tells us that the partition of the children is into singletons.

(70) a. These four children sleep one above the other.

b. These four children sleep above each other.

\section{Conclusions}

To summarize, we subscribe to the view that all pluralization is sensitive to a division of pluralities into appropriate subparts. Pluractionals make this visible; in our cases with 'piece by piece' and 'dog after dog', they tell us which units are contained in the cover. They also show that natural language has pluralization of $\langle\mathrm{e},\langle\mathrm{v}, \mathrm{t}\rangle\rangle$ predicates, i.e. simulataneous pluralization of an event- and an individual-argument slot. Adverbials 'one ... the other' are a case of such pluractionals which gives rise to a sequence interpretation that we have called pseudoreciprocal.

If IAO reciprocals are reanalyzed as pseudoreciprocals (i.e. pluractional 'one ... the other'), this may explain some peculiarities that otherwise set apart IAO reciprocals from better behaved reciprocals. Pseudoreciprocals would be different from regular reciprocals in not introducing a plurality of type $\langle\mathrm{e}\rangle$. Rather, they are a modifier containing a singular 'the other' NP.

Let us also point out what is still missing from the discussion here. One caveat is empirical. Not all 'Noun Preposition Noun' modifiers share the pseudoreciprocal semantics proposed here for 'one ... the other'. One ought to relate the semantic contribution of modifiers like 'leaf by leaf', 'two and two', 'side by side' to our pluractionals.

The other omission is a detailed comparison of our analysis to related proposals. Let us briefly explain how we perceive the relation of our analysis to Moltmann (1995) on the one hand and Stockall/Zimmermann on the other. Moltmann suggests a semantics for pluractional 'one at a time' (extendable to 'piece by piece'-type adverbials) which is based on simultaneous division of events into subevents and entities into subparts. She thus anticipates this aspect of our analysis. It is, however, embedded into a different architecture, in that her views of the syntax-semantics interface and pluralization operations in particular, are incompatible with 
our own. The same is true of Stockall/Zimmermann's analysis of 'dog after dog'. Like Moltmann, they hold the adverbial itself and/or its composition within its local structure responsible for all of the specific semantics of the construction. Our analysis has been guided by the idea that we have a system of plural predication in place independently which includes plural operators of various types plus a restriction on relevant part-whole structures. Thus the adverbial has a very slim semantics, with much of the burden to be carried by the pluralization operation. A more thorough discussion that includes an empirical comparison with other works must wait until a future occasion.

\section{References}

Beck, Sigrid. 2001. Reciprocals are Definites. Natural Language Semantics 9:69-138.

Dalrymple, Mary et al. 1998. Reciprocal Expressions and the Concept of Reciprocity. Linguistics and Philosophy 21:159-210.

Fiengo, R., and Lasnik, H. 1973. The Logical Structure of Reciprocal Sentences in English. Foundations of Language 9:447-468.

Heim, Irene, Lasnik, Howard, and May, Robert. 1991. On "Reciprocal Scope". Linguistic Inquiry 22:173-192.

Lasersohn, P. 1995. Plurality, Conjunction and Events. Boston: Kluwer Academic Publishers.

Lewis, David. 1991. Parts of Classes. Oxford: Basil Blackwell.

Link, G. 1983. The Logical Analysis of Plurals and Mass Terms: A Lattice-Theoretical Approach. In Meaning, Use, and Interpretation of Language, eds. R. Bäuerle, C. Schwarze and A. v. Stechow, 302-323. Berlin: de Gruyter.

Moltmann, Friederike. 1995. Parts and Wholes in Semantics. Oxford: Oxford University Press.

Schwarzschild, R. 1996. Pluralities: Studies in Linguistics and Philosophy. Dordrecht: Kluwer.

Sternefeld, Wolfgang. 1998. Reciprocity and Cumulative Predication. Natural Language Semantics: 303-337.

Stockall, L. 2001. Pluriactionality and Prepositions in Germanic. The Syntax and Semantics of [NP-P-NP]s. In ConSole X. Leyden.

Zimmermann, Malte. 2002. Boys Buying Two Sausages Each. On the Syntax and Semantics of Distance-Distributivity, Universiteit van Amsterdam: Dissertation. 